\title{
Hydrocarbon soluble metal corrosion inhibitors. I. Physicochemical aspects of the choice of starting products and synthetic reactions
}

\author{
A. I. Altsybeeva,* V. V. Burlov, E. A. Tronova, T. M. Kuzinova \\ and G. F. Palatik \\ All-Russia Research Institute of Petrochemical Processes, Zheleznodorozhnyi pr. 40, \\ St. Petersburg, 192148 Russian Federation \\ E-mail: altsybeeva@yandex.ru
}

\begin{abstract}
The relationship between the physicochemical and electronic characteristics of inhibitors that allows one to forecast the efficiency of metal corrosion inhibitors in waterhydrocarbon media is discussed. It has been shown that the main molecular characteristics of aliphatic acid amides obtained from nitrogen-containing compounds with one amino group and an N-methylolcaprolactam ester make it possible to forecast that they should have high efficiency as corrosion inhibitors in hydrocarbon media.
\end{abstract}

Key words: hydrocarbon-soluble metal corrosion inhibitors; choice of starting products and synthetic reactions; efficiency forecasting; aliphatic amides; $N$-methylolcaprolactam ester.

Received: December 24, 2013/

doi: $\underline{10.17675 / 2305-6894-2014-3-1-066-077}$

Currently, Russian oil refinery plants mainly protect equipment of crude oil distillation units using imported amidoimidazoline inhibitors. Unfortunately, experience of their application suggests that the efficiency of industrial products purchased abroad varies from batch to batch and that the inhibitor efficiency decreases abruptly during storage in plant warehouses [1-4].

In some instances, it was observed at oil refinery plants that after a purchased batch had been stored for three to six months, the inhibitor efficiency decreased 4-5 fold, which demanded for a considerable increase in its "working" concentration. It has been established reliably that industrial inhibitors of amidoimidazoline series are characterized by "ageing", i.e., variation in the technical, protective and physicochemical characteristics in the course of time: product stratification, a decrease in solubility in hydrocarbons, and abrupt (sometimes by an order of magnitude) decrease in protective properties [1-4].

No efficient methods to avoid these phenomena have been suggested in the world literature and practice. Reactions resulting in "ageing" are inevitable, since they are determined by the chemical structure of compounds and by conditions of industrial production and storage [1-4]. Furthermore, the thermal stability of amidoimidazoline 
inhibitors does not exceed $160-180^{\circ} \mathrm{C}$. This is an important factor that prevents their use in the new (full) scheme of inhibitor protection of crude oil distillation units $[5,6]$.

Of domestic corrosion inhibitors, the IKB-2-2 [7-9] and VNKh-1 inhibitors [10-13] have successfully passed industrial tests and have been accepted for application in all types of units, including those producing straight-run jet fuels. IKB-2-2 is an amidoimidazoline inhibitor and thus it features all the drawbacks that imported inhibitors of this series have. Large-scale industrial production of IKB-2-2 was not implemented due to insufficient availability of the raw materials at that time.

VNKh-1 (a mixture of esters of N-oxyethylenecaprolactam with synthetic fatty acids $\mathrm{C}_{10}-\mathrm{C}_{16}$ ) showed high efficiency and multifunctionality, since it ensured not only protection of steel and brass equipment under crude oil distillation conditions but also protection of a broad range of ferrous and non-ferrous metals from atmospheric corrosion (when used as an additive to preservative oils and lubricants) [12-14]. However, its industrial large scale production was not implemented either, both due to the economic situation in our country and to the specific features of the industrial production scheme: the synthesis has to be carried out in two stages, in two reactors of different design.

All the facts described above dictate the necessity to develop a new domestic hydrocarbon-soluble multifunctional corrosion inhibitor that can find use not only in oil extraction and treatment but also in preservation of items of machine-building, bearing, and other industries. Development of such an inhibitor will make a number of branches of national economy import-independent.

Let us consider some molecular aspects of the protective action and specific behavior of hydrocarbon-soluble corrosion inhibitors in water-organic environments. We believe that these aspects make it possible to forecast inhibitor efficiency based on calculated physicochemical parameters using the main approaches employed in the development of VNKh-1 inhibitor [14].

According to the concept currently shared by the majority of researchers, the protective effect of hydrocarbon soluble corrosion inhibitors in water-organic and hydrocarbon media is explained by the "three-layered" mechanism involving the so called "sandwich" structure [15]. The bottom layer of the "sandwich" is formed by polar inhibitor groups that are bound with the metal surface. Its effect on the inhibitive capability is determined by the strength of the adsorption bond with the metal. The middle layer is formed by nonpolar molecule parts and its effect is determined by the degree of surface wetting or screening that these molecule parts can create. The outer "sandwich" layer is a hydrophobic "oily" layer formed by molecules of the hydrocarbon phase trapped by the adsorption film.

The mechanism of the protective action of hydrocarbon soluble corrosion inhibitors can be considered as a combination of sequential stages:

- displacement of water (aqueous electrolyte solution) from the metal surface by the inhibitor; 
- formation of protective adsorption layers on the metal;

- formation of a protective film layer under the effect of adhesion forces, and finally

- the screening effect of the resulting layer itself.

As concerns accounting the specifics of the electronic structure, hydrocarbon soluble inhibitors do not differ from other organic corrosion inhibitors. On the other hand, knowledge of only the electronic structures is insufficient for the understanding and forecasting of their protective properties. A specific feature of the interaction of hydrocarbon soluble inhibitors with a metal surface is that the formation of hydrophobic protective adsorption layers with complex structures occurs in the course of time. As the contact time increases, an increase in the barrier and screening properties of adsorption films is observed. Adsorption is irreversible to a considerable degree, as indicated by the protection post-effect. It is the post-effect that is a characteristic distinctive feature of longchain inhibitors providing "sandwich" type metal protection in water-organic environments.

Two opposite properties are required from an efficient corrosion inhibitor in hydrocarbon media. On the one hand, in order to be adsorbed on a metal, an inhibitor should at least be dispersed in the corrosive environment. On the other hand, the adsorbed inhibitor should not be easily dispersible. The balance of hydrophilic and oleophilic groups in its molecule should differ from the similar values for usual surfactants. An increase in the number of hydrophilic groups in an inhibitor molecule in order to increase its solubility (dispersability) does not always considerably increase adsorptivity.

To choose the starting compounds and reactions for synthesizing new hydrocarbon soluble corrosion inhibitors, let us use the approach suggested in $[17,18]$ (and generalized in [14]), which is based on a thermodynamic analysis of criteria of surface activity of organic compounds and estimation of their metal affinity ("metallophilicity") depending on their electronic structure, as well as using published data on the most efficient classes of corrosion inhibitors in hydrocarbons [1, 4].

Hindrance of metal corrosion in the presence of organic surface active compounds (surfactants) results from competitive adsorption of inhibitor and water molecules on the metal surface. Based on the principles of thermodynamic equilibrium between the components of the bulk phase and adsorption film, a general equation of the adsorption isotherm for an organic surfactant on a metal from a dilute aqueous solution was suggested [17]:

$$
R T \ln \left[\frac{f_{\text {i.ads }} x_{\text {i.ads }}\left(f_{\text {w.b }} x_{\text {w.b }}\right)^{n}}{f_{\text {i.b }} x_{\text {i.b }}\left(f_{\text {w.ads }} x_{\text {w.ads }}\right)^{n}}\right]=n \Delta F_{\text {w }}-\Delta F_{\text {i }},
$$

where: $x_{\text {i.b }}, x_{\mathrm{w} . \mathrm{b}}, x_{\text {i.ads }}$, and $x_{\mathrm{w} \text {.ads }}$ are the molar fractions of the inhibitor and water in the bulk phase and in the adsorption film, respectively; $f_{\text {i.b }}, f_{\text {w.b }}, f_{\text {i.ads, }}$, and $f_{\text {w.ads }}$ are the activity coefficients corresponding to the previous designations; $\Delta F_{\mathrm{w}}$ is the change in free energy due to transfer of one mole of water from the bulk phase to the adsorption film; $\Delta F_{\mathrm{i}}$ is a 
similar value for the inhibitor; and $n$ is the number of water molecules displaced by an inhibitor molecule upon adsorption on the metal.

Detailed analysis of applications of equation (1) generalized in [14] has shown that, if the surface fraction occupied by an organic compound is $\theta$ and that for water is $(1-\theta)$, then for compounds similar in properties, e.g., homologues, it is possible to expand $\theta$ into a Taylor series in the neighborhood of a point corresponding to the averaged properties of the homologous series and to restrict oneself to the linear members

$$
\theta=\alpha+\beta x_{\mathrm{i} . \mathrm{b}}+\gamma\left(-\Delta F_{\mathrm{i}} / R T\right)+\delta n,
$$

where $\alpha, \beta$, and $\gamma$ are partial derivatives and

$$
\partial \theta / \partial x_{\mathrm{i}}>0 ; \partial \theta / \partial\left(\Delta F_{\mathrm{i}} / R T\right)>0 ; \partial \theta / \partial n<0 .
$$

For the thermal solution model, expression (2) is transformed to

$$
\theta=\alpha+\beta x_{\mathrm{i} . \mathrm{b}}+\gamma\left(-\Delta F_{\mathrm{i}} / R T\right)+\tau(\varepsilon / R T)+\delta n,
$$

where $\varepsilon=\varepsilon_{\mathrm{i}-\mathrm{w}}-\left(\varepsilon_{\mathrm{i}-\mathrm{i}}+\varepsilon_{\mathrm{w}-\mathrm{w}}\right) / 2$ represents intermolecular interaction by characterizing the solution deviation from ideality and

$$
\tau=\partial \theta / \partial \varepsilon>0
$$

The $\varepsilon_{\mathrm{i}-\mathrm{i}}, \varepsilon_{\mathrm{w}-\mathrm{w}}$, and $\varepsilon_{\mathrm{i}-\mathrm{w}}$ values are the molar potential energies of interaction of molecules located in the adsorption centers of adjacent pairs, respectively: "inhibitorinhibitor", "water-water", and "inhibitor-water".

Theoretical analysis of expressions (2) and (4) with the use of partial derivatives (3) and (5) made it possible [14, 17-19] to identify the main ways to increase the adsorptivity of organic inhibitors on metals, namely, introduction of groups that increase hydrophobicity (derivative 5) and affinity to the adsorbent (derivative 6) in an inhibitor molecule:

$$
\partial \theta / \partial\left(\Delta F_{\mathrm{i}} / R T\right)>0
$$

As the length of the aliphatic radical increases, the $\varepsilon$ value also increases, whereas solubility $\left(x_{\mathrm{i} . \mathrm{b}}\right)$ decreases and $n$ increases. The optimum efficiency of hydrocarbon soluble surfactants is attained with a chain length of 12-16 (12-14) carbon atoms. Moreover, inhibitors synthesized from a mixture of acids are more efficient that those synthesized from pure acids with the same chain length [16].

It follows from expressions (2), (4) and partial derivatives (3), (5), (6) that increasing the adsorptivity (and efficiency) of inhibitors from dilute solutions on metals can be reached by introducing groups that increase the "metallophilicity" and hydrophobicity of an inhibitor [17-19]. Of compounds with equal "metallophilic" and hydrophobic properties, preference should be given to those which occupy a smaller molar surface area in adsorbed state (in an adsorption film). This becomes clear if one takes into consideration that adsorption of molecules which occupy a larger area on the metal should be 
accompanied by displacement of more water molecules from the surface, which is energetically unfavorable for adsorbents well wettable with water, such as metals.

It was suggested to use the electronic density on heteroatoms [20] or the energy of formation of a "metal-inhibitor" complex [21-24] as the electronic characteristics of inhibitor affinity to a metal. We believe that these characteristics can be used to forecast the protective properties of inhibitors belonging not only to one series but also to different reaction series.

Thus, the efficiency of a hydrocarbon soluble inhibitor is determined by:

- electron density on the heteroatoms that are presumably responsible for the formation of the adsorption layer ("anchor" atoms) $\left(\sum q\right)$;

- hydrophobicity (e.g., the Hansch hydrophobicity constant $\pi$ );

- molecule size (molar surface area or $n$, that is, the number of water molecules displaced by the inhibitor from the metal surface due to adsorption).

This means that the degree of metal protection by an inhibitor in hydrocarbon environments is mainly a function of $\sum q, \pi$, and $n$.

Taking into consideration the published data on the main classes of hydrocarbon soluble inhibitors and experience with amidoimidazoline inhibitors, we believe that it is most expedient to search for new corrosion inhibitors among amides and esters.

Table 1 demonstrates data on electron density and Hansch $\pi$-constants of the starting compounds for the planned syntheses. Table 2 shows the calculated parameters of amides and esters, as well as imidazolines recommended in the world practice.

Table 1. Electron densities on heteroatoms $\left(\sum q\right)$ and Hansch $\pi$-constants of starting compounds for the synthesis of amides and esters.

\begin{tabular}{ccc}
\hline Compound & $\boldsymbol{\pi}$-constant & $\Sigma \boldsymbol{q}$ \\
\hline Cyclohexylamine & 1.74 & 1.221 \\
Hexylamine & 2.03 & 1.211 \\
Morpholine & -0.98 & 2.394 \\
Caprolactam & -0.83 & 2.575 \\
\hline
\end{tabular}

The following abbreviations for the products are used in Table 2: DETrA diethylenetriamine; TETA - triethylenetetramine; CL - caprolactam; MF - morpholine; CHA - cyclohexylamine; HA - hexylamine; AM - amide; IM - imidazoline. All the calculations were carried out for compounds provisionally synthesized from $\mathrm{C}_{12} \mathrm{H}_{25} \mathrm{COOH}$ $\left(\mathrm{C}_{10}-\mathrm{C}_{16}\right.$ fraction, $\mathrm{C}_{13}$ on average $)$. 
Table 2. Main physicochemical parameters of corrosion inhibitors (the calculations were carried out for compounds provisionally synthesized from $\mathrm{C}_{12} \mathrm{H}_{25} \mathrm{COOH}$ (fraction $\mathrm{C}_{10}-\mathrm{C}_{16}$, average: $\mathrm{C}_{13}$ ).

\begin{tabular}{cccccc}
\hline Conventional name & Compound & $\boldsymbol{\pi}$ & $\sum \boldsymbol{q}$ & $\boldsymbol{A} \cdot \mathbf{1 0} \mathbf{8} \mathbf{c m}^{\mathbf{2}}$ & $\boldsymbol{n}$ \\
\hline IM-1 & Imidazoline based on & 3.74 & 3.663 & 38.8 & 6.72 \\
IM-2 & DETrA & & & 7.12 \\
Imidazoline based on & 2.31 & 4.845 & 41.3 & \\
AM-1 & TETA & & & 6.99 \\
AM-2 & DETrA amide & 1.78 & 4.964 & 40.5 & 7.64 \\
AM-MF & TETA amide & 0.59 & 6.145 & 44.2 & 6.73 \\
AM-CL & MF amide & 3.23 & 3.750 & 38.9 & 6.99 \\
AM-CHA & CL amide & 3.41 & 3.808 & 40.5 & 6.98 \\
AM-HA & CHA amide & 6.59 & 2.592 & 40.3 & 6.98 \\
VNKh-2M & HA amide & 7.00 & 2.584 & 40.4 & 7.21 \\
VNKh-1M & N-methylolMF ester & 1.83 & 4.938 & 41.7 & 7.44 \\
VNKh-1 & N-methylolCL ester & 2.01 & 5.097 & 43.1 & 7.65 \\
\hline
\end{tabular}

Designations in Table 2: $A$ - molar surface; $n$ - number of water molecules displaced from the metal surface upon inhibitor adsorption; $\pi$ - Hansch hydrophobicity constant; $\sum q$ - total electron density on the heteroatoms in the molecule.

The molar surface area $A\left(\right.$ in $\left.\mathrm{cm}^{2}\right)$ was calculated by the formula [25, p. 84]:

$$
A=V^{2 / 3} N_{\mathrm{A}}^{1 / 3} / n,
$$

where $V$ is the molar volume ( $V=$ molecular mass/density); $N_{\mathrm{A}}$ is the Avogadro number; $n$ is the number of monolayers in the surface layer of the pure compound (we assumed $n=1$ in the calculations). The density of all compounds planned for synthesis was provisionally (for comparison of the products) assumed to be equal to $0.9 \mathrm{~g} / \mathrm{cm}^{3}$.

The hydrophobicity constants $\lg P$ (Hansch $\pi$-constants) were calculated using the C. Hansch method [26, Ch. IV]. The quantum-chemical calculations of molecular diagrams were carried out using HyperChem Version Professional Release 6.03 software from Hypercube Inc. (C) 2001 by the $\mathrm{CNDO} / 2$ method without optimization. Standard bond lengths and bond angles were used. The Build model was set in the Single Point mode.

It follows from the quantum-chemical calculations of molecular diagrams of the starting compounds for the synthesis of amides and esters that caprolactam and morpholine have the highest metal affinity (Table 1). On the other hand, according to Hansch constants, these compounds are hydrophilic, unlike hexylamine and cyclohexylamine. This undoubtedly affects the hydrophilic-hydrophobic balance of the derivatives, decreasing their hydrophobicity for the same chain length in the hydrophobic moiety. 
In fact (Table 2), amides derived from caprolactam and morpholine are less hydrophobic than amides of hexylamine and cyclohexylamine. Esters of $\mathrm{N}$ methylolcaprolactam and $\mathrm{N}$-methylolmorpholine are less hydrophobic than the corresponding amides because a hydrophilic ester group was introduced into their structures. Polyamine amides that have high electron density on the heteroatoms still have the lowest hydrophobicity due to the presence of hydrophilic free amino groups in their structure.

An optimum ratio of electronic properties and hydrophobicity is characteristic of amides and esters of $\mathrm{N}$-methylolmorpholine and $\mathrm{N}$-methylolcaprolactam. Though amides of hexylamine and cyclohexylamine have high hydrophobicity, the electron density on their heteroatoms is lower than in other amides.

The sizes of all the compounds are similar. However, here we have to take into account the assumptions underlying the model used to calculate the molar surfaces and hypothetic number of water molecules displaced from the metal upon inhibitor adsorption. In terms of the possible molecule arrangement on the metal surface upon adsorption, preferable inhibitors should have a "compact" layout of the "anchor" atoms, i.e., such as amides of hexylamine, cyclohexylamine, and caprolactam, as well as Nmethylolcaprolactam ester (VNKh-1M).

For this reason, the rather high electronic and hydrophobic characteristics of DETrA and TETA imidazolines (IM-1 and IM-2) cannot be the reason for forecasting their efficiency to be higher than that of AM-CL, AM-HA, AM-CHA and ester VNKh-1M; the opposite prediction would be more likely. In fact, it has been shown [27] that the hydrophilic part at position 1 of the imidazoline ring is not of primary importance for the adsorption of the imidazoline molecule on the metal surface and efficiency is determined by the length of the hydrophobic chain at position 2. It was assumed in [27] that imidazolines form a bond with the metal through the five-membered ring that is arranged in a planar way. The role of the hydrocarbon chain at position 2 consists of surface hydrophobization and creation of a barrier for corrosive components (Fig. 1).

The electron densities on the heteroatoms in the molecules of some compounds in question that can illustrate these ideas are provided below.

IM-2 - Imidazoline based on tetraethylenetetramine

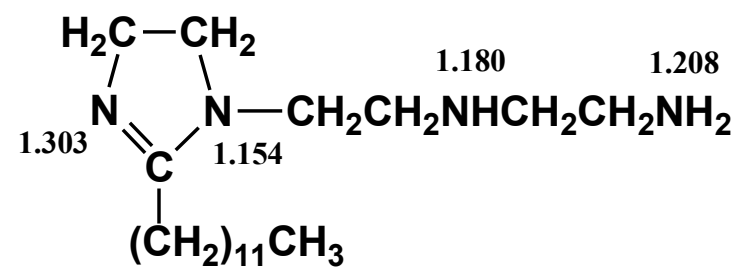
AM-2 - Triethylenetetramine amide

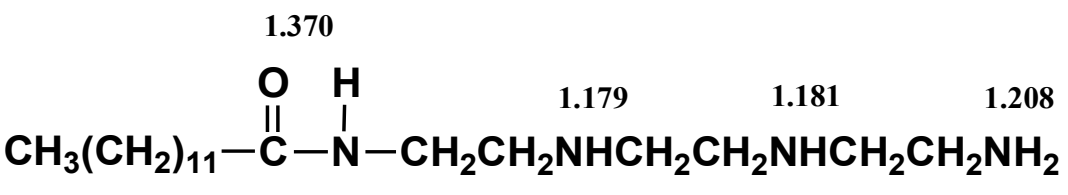


AM-MF - Morpholine amide

AM-CL - Caprolactam amide<smiles>CCCCC(=O)N1CCOCC1</smiles>

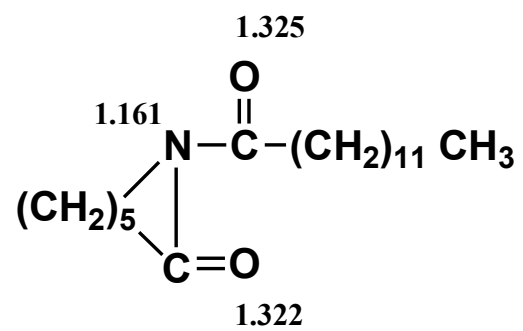

AM-HA - Hexylamine amide

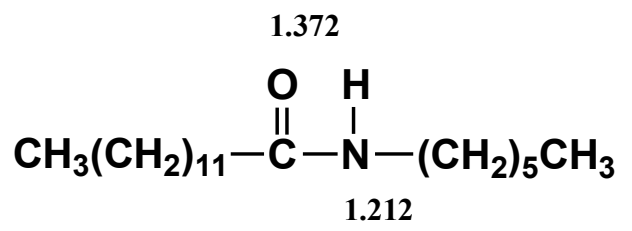

VNKh-2M - N-methylolmorpholine ester

VNKh-1M - N-methylolcaprolactam ester

VNKh-1 - N-oxyethylenecaprolactam ester

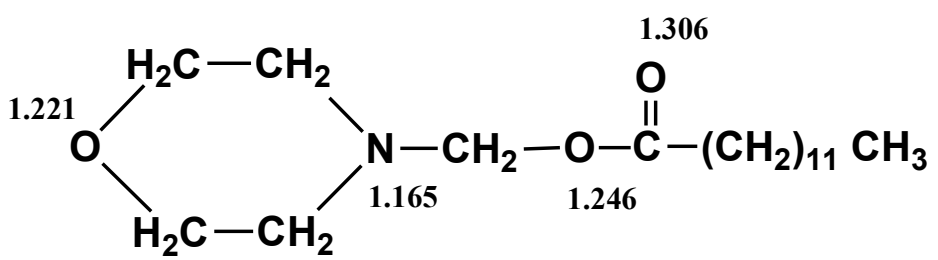

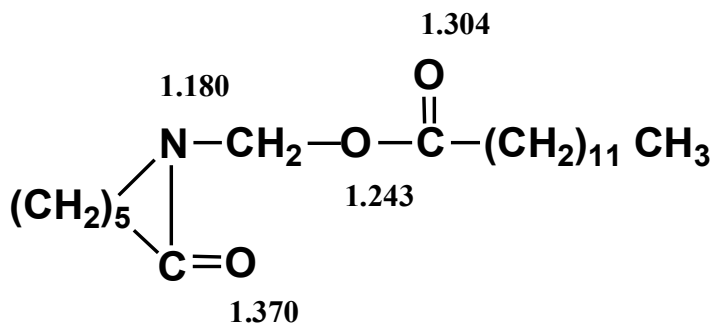

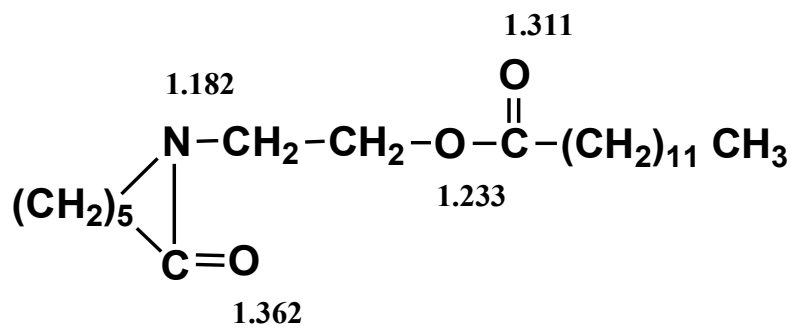



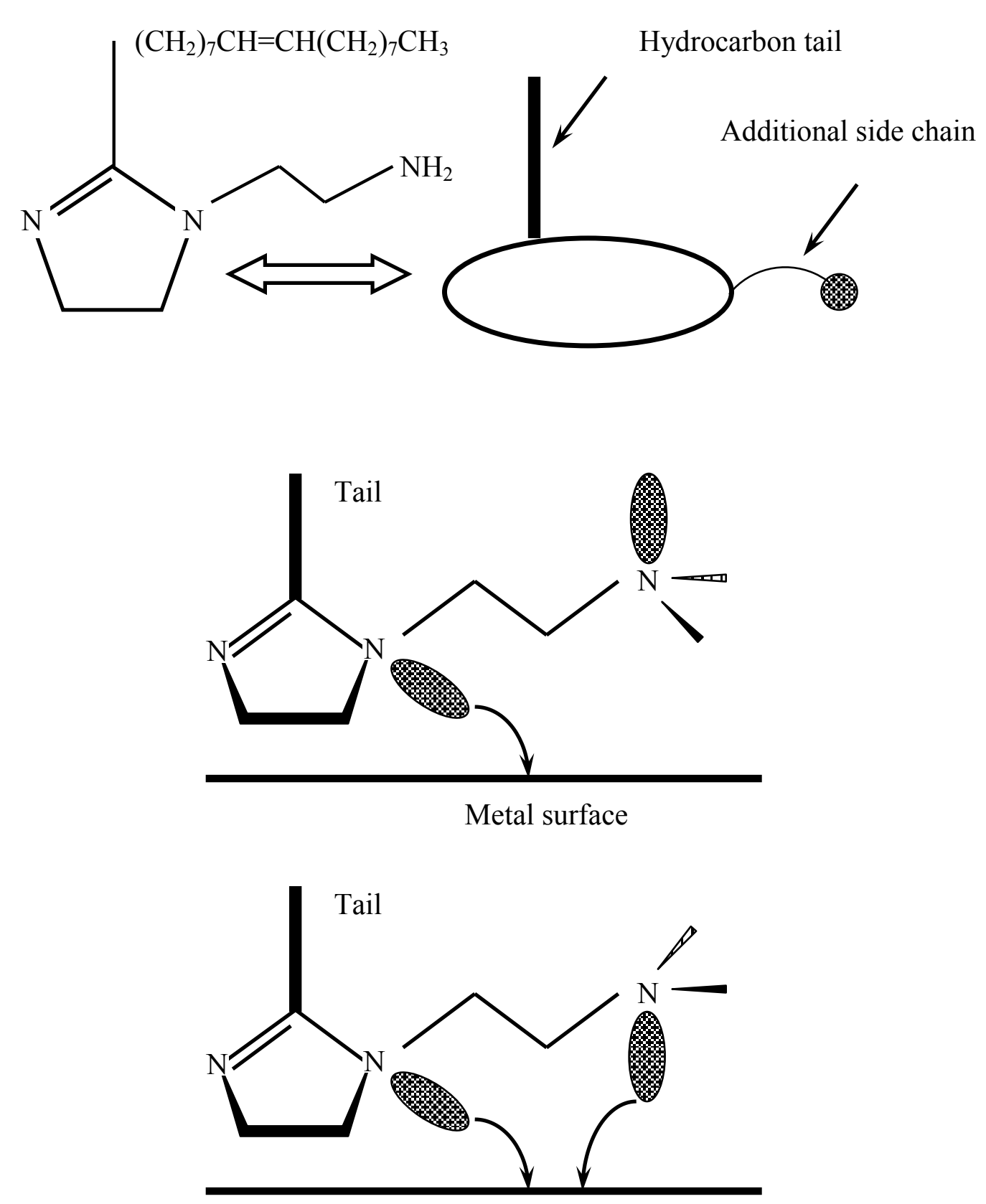

Metal surface

Figure 1. Hypothetic model of imidazoline inhibitor adsorption on a metal surface (according to [27]).

Without dwelling on the issues related to the "ageing" of amidoimidazoline inhibitors mentioned above, let us note the inevitable formation of large amounts of ammonium salts during the synthesis of imidazolines (or amides) from polyamines and their role of a "ballast" in the end product, as described in sufficient detail in [1]. 
However, it can be believed with certainty that similar phenomena that decrease the inhibitive efficiency of the end products would not occur for inhibitors obtained by hightemperature heterogeneous catalytic synthesis of amides (and even more so, esters) based on products containing one amino group.

With high probability, the efficiency of N-methylolcaprolactam ester should not be lower than that of the VNKh-1 inhibitor (N-oxyethylenecaprolactam ester). However, unlike VNKh-1, it can be produced on industrial scale using a one-reactor scheme, so it has an advantage over VNKh-1 in this respect. This is equally true for cyclohexylamine and hexylamine amides.

\section{Conclusions}

1. Aspects of the relationship between the physicochemical and electronic characteristics of inhibitors that allow one to forecast the efficiency of metal corrosion inhibitors in water-hydrocarbon media are considered.

2. An approach based on thermodynamic analysis of the criteria of the surface activity of organic compounds and estimation of their affinity to a metal ("metallophilicity") based on electronic structure was used to select the starting compounds and reactions for synthesizing new hydrocarbon soluble corrosion inhibitors.

3. It has been substantiated how the inhibitor efficiency in water-hydrocarbon environments depends on the electron density on the molecule heteroatoms presumably responsible for the formation of the adsorption layer ("anchor" atoms), hydrophobicity (Hansch hydrophobicity $\pi$-constants), and molecule size (molar surface or the number of water molecules displaced by the inhibitor from the metal surface during adsorption).

4. It has been shown that, from the point of view of possible arrangement of the molecule on the metal surface upon adsorption, inhibitors with "compact" arrangement of the "anchor" atoms in the molecule are preferable.

5. Based on the calculated main molecular characteristics of aliphatic acid amides obtained from nitrogen-containing compounds with one amino group and an $\mathrm{N}$ methylolcaprolactam ester, their high efficiency as corrosion inhibitors in hydrocarbon media has been forecasted.

\section{References}

1. V. V. Burlov, A. I. Altsybeeva and I. V. Parputs, Zashchita ot korrozii oborudovaniya NPZ (Corrosion protection of oil refinery equipment), Saint Petersburg, Khimizdat, 2005 (in Russian).

2. A. I. Altsybeeva, V. V. Burlov, T. M. Kuzinova, G. F. Palatik and S. M. Reshetnikov, Proc. $10^{\text {th }}$ Europ. Symp. on Corrosion Inhibitors, Ann. Univ. Ferrara, N. S., V.2, 2005, 551.

3. A. I. Altsybeeva, V. V. Burlov, T. M. Kuzinova, G. F. Palatik and S. M. Reshetnikov, Korroz.: mater., zashch., 2006, no. 1, 25 (in Russian). 
4. N. A. Gafarov, V. M. Kushnarenko, D. E. Bugai et al., Ingibitory korrozii (Corrosion inhibitors), vol. 2, Moscow, Khimiya, 2002 (in Russian).

5. A. I. Altsybeeva, V. V. Burlov, G. F. Palatnik and V. L. Sokolov, Korroz.: mater., zashch., 2007, no. 5, 23 (in Russian).

6. A. I. Altsybeeva, V. V. Burlov, G. F. Palatnik and V. L. Sokolov, Vestnik UdGU, Ser. Khim., 2006, no. 8, 3 (in Russian).

7. V. V. Fryazinov, A. K. Efimova and V. N. Umutbaev, Ekspluatatsiya, modernizatsiya $i$ remont oborudovaniya $v$ neftepererabatyvayushchei $i$ neftekhimicheskoi promyshlennosti (Operation, renovation and repair of equipment in oil processing and petrochemical industries), NTRS, Moscow, TsNIITENeftekhim, 1979, no. 4, 14 (in Russian).

8. M. F. Surova, Ekspluatatsiya, modernizatsiya $i$ remont oborudovaniya $v$ neftepererabatyvayushchei i neftekhimicheskoi promyshlennosti (Operation, renovation and repair of equipment in oil processing and petrochemical industries), NTRS, Moscow, TsNIITENeftekhim, 1979, no. 8, 10 (in Russian).

9. V. N. Umutbaev and V. T. Savkova, Khimiya i tekhnologiya topliv $i$ masel, 1990, no. 10, 4 (in Russian).

10. A. I. Altsybeeva, B. M. Teslya, L. F. Tishkevich et al., Ekspluatatsiya, modernizatsiya $i$ remont oborudovaniya $v$ neftepererabatyvayushchei $i$ neftekhimicheskoi promyshlennosti (Operation, renovation and repair of equipment in oil processing and petrochemical industries), NTRS, Moscow, TsNIITENeftekhim, 1981, no. 4, 16 (in Russian).

11. A. I. Altsybeeva, L. F. Tishkevich, L. B. Sokolova et al., Neftepererabotka $i$ neftekhimiya, 1981, no. 12, 11 (in Russian).

12. A. I. Altsybeeva, T. M. Kuzinova, L. F. Tishkevich et al., USSR Author's Certificate 1213718, Int. $\mathrm{Cl}^{3}{ }^{3}$ C 07 D223/10, C23F 11/14, no. 3378070, Submitted 17.11.81, published 22.10.85 (in Russian).

13. A. I. Altsybeeva and T. M. Kuzinova, $R F$ Patent 2225465, Int. Pat. Cl. ${ }^{7}$ C 23 F 11/14, no. 2002103980; Submitted 12.02.2002, Published 10.03.2004, Bull. no. 7 (in Russian).

14. A. I. Altsybeeva, T. M. Kuzinova and E. M. Agres, Zashch. Met., 2003, 39, no. 3, 1 (in Russian).

15. G. I. Bregman, Corrosion Inhibitors, Mac-Millan, New York, 1963.

16. E. M. Agres, A. I. Altsybeeva and T. M. Kuzinova, Zh. Prikl. Khim., 1987, 60, no. 2, 287 (in Russian).

17. E. M. Agres, A. I. Altsybeeva, S. Z. Levin and V. S. Fedorov, Zh. Fiz. Khim., 1975, 49, no. 4, 986 (in Russian).

18. E. M. Agres, A. I. Altsybeeva, S. Z. Levin and V. S. Fedorov, Zh. Fiz. Khim., 1977, 51, no. 1, 168 (in Russian).

19. E. M. Agres, A. I. Altsybeeva, S. Z. Levin and V. S. Fedorov, Zh. Fiz. Khim., 1977, 51, no. 2, 421 (in Russian). 
20. A. I. Altsybeeva, A. P. Dorokhov and S. Z. Levin, Proc. $3^{\text {rd }}$ Europ. Symp. on Corrosion Inhibitors (Ferrara, 1970), Annali dell' Universita di Ferrara, N.S.- Sez. V. 1971, 501.

21. E. M. Agres, A. I. Altsybeeva, S. Z. Levin and V. S. Fedorov, Proc. $5^{\text {th }}$ Int. Congress on Metallic Corrosion (Tokyo, 1972), 1974, 528.

22. E. M. Agres, A. I. Altsybeeva, S. Z. Levin and V. S. Fedorov, Zh. Fiz. Khim., 1976, 50, no. 1263152 (in Russian).

23. E. M. Agres, A. I. Altsybeeva, S. Z. Levin and V. S. Fedorov, Zh. Fiz. Khim., 1977, 51, no. 1, 165 (in Russian).

24. E. M. Agres and A. I. Altsybeeva, Zh. Fiz. Khim., 1976, 50, no. 12, 3149 (in Russian).

25. A. I. Rusanov, Fazovye ravnovesiya i poverkhnostnye yavleniya (Phase Equilibria and Surface Phenomena), Leningrad, Khimiya, 1967 (in Russian).

26. C. Hansch and A. Leo, Substituent Constants for Correlation Analysis in Chemistry and Biology, New York, John Willey \& Sons, 1981.

27. A. Edwards, C. Osborne, S. Webster, D. Klenerman, M. Joseph, P. Ostovar and M. Doyle, Corros. Sci., 1994, 36, no. 2, 315. 